\title{
Glucose Biosensing Using Glassy Carbon Electrode Modified with Polyhydroxy-C60, Glucose Oxidase and Ionic-liquid ${ }^{1}$
}

\author{
Tian Yang ${ }^{\mathrm{a}}$, Xiao-Lu Yang ${ }^{\mathrm{a}}$, Yu-Shuai Zhang ${ }^{\mathrm{a}}$, BaoLin Xiao ${ }^{\mathrm{a}}$ and Jun Hong, ${ }^{\mathrm{a}, \mathrm{b}}{ }^{*}$ \\ ${ }^{a}$ School of Life Sciences, Henan University, Kaifeng 475000, China \\ ${ }^{b}$ Institute of Biotechnology, Henan University, Kaifeng 475000, China
}

\begin{abstract}
Direct electrochemistry of glucose oxidase (GOD) was achieved when an ionic liquid/GOD-Polyhydroxy-C60 functional membrane was confined on a glassy carbon electrode (GCE). The cyclic voltammograms (CVs) of the modified GCE showed a pair of redox peaks with a formal potential $\left(E^{\circ}\right)$ of $-329 \pm 2 \mathrm{mV}$. The heterogeneous electron transfer constant $\left(\mathrm{k}_{\mathrm{s}}\right)$ was $1.43 \mathrm{~s}-1$. The modified GCE response to glucose was linear in the range from 0.02 to $2.0 \mathrm{mM}$. The detection limit was $1 \mu \mathrm{M}$. The apparent Michaelis-Menten constant $\left(\mathrm{K}_{\mathrm{m}}^{\mathrm{app}}\right)$ was $1.45 \mathrm{mM}$.
\end{abstract}

Keywords: Glucose oxidase, polyhydroxy-C60, ionic liquid, direct electrochemistry

\section{Introduction}

Fullerenes are outstanding stable clusters, consisting of sp2-hybridized carbon atoms arranged in a 3D structure with a sphere-like shape [1-3] and characterized by hydrophobicity, high thermal stability and stability to oxidation [4]. Functionalized fullerene derivatives have been used in the areas of nanotechnology and materials science because of their unique photophysical and electrochemical properties [5]. Polyhydroxy-C60 (PHC) is a water soluble functionalized fullerene derivatives [6,7]. PHC could link with a protein and form specific complex, and could be used to protect proteins [8].

Ion liquids (IL) can form organized polymeric supramolecules containing polar and non-polar regions in either liquid or solid states $[9,10]$. In solution, proteins (or enzymes) could be embedded in IL network, and the native structure of proteins could be preserved [10-12].

In this work, a functional membrane was improved by using IL (1-Butyl-3-methyl imidazolium tetrafluoroborate, [BMIM] $\mathrm{BF}_{4}{ }^{-}$), Glucose oxidase (GOD) and PHC. Noncovalent linking (hydrogen bond, van der vals or hydrophobicity interactions) between GOD and PHC in IL membrane have been formed, which may help to preserve the stability of GOD's structure and function. Direct electron electrochemistry of GOD was achieved when the functional membrane was confined on a glassy

\footnotetext{
${ }^{1}$ Tian Yang, Xiao-Lu Yang and Yu-Shuai Zhang contributed equally to this work.

${ }^{*}$ Corresponding author: Jun Hong, School of Life Sciences, Henan University, Kaifeng 475000, China. Tel.: +86 13781161597; Fax: +86 371 23886258; E-mail: hongjun@henu.edu.cn.
} 
carbon electrode (GCE). The modified electrode could be used as a new type biosensor for detection of glucose with good sensitivity, stability and selectivity.

\section{Experimental}

\subsection{Reagents and apparatus}

GOD (from aspergillus niger), 1-Butyl-3-methyl imidazolium tetrafluoroborate (IL) and $\alpha$-D-glucose were purchased from Sigma (Saint Louis, MO, USA). PHC was obtained from Bucky (Houston, USA). Hydrogen peroxide was from Shanghai Chemicals Company (Shanghai, China). All other chemicals were of analytical grade and used without further purification. All solutions were prepared in double-distilled deionized water.

All electrochemical experiments were carried out in a three electrode cell electrochemical system (CHI650C, CHI Instrument, Austin, USA). A Pt wire, an $\mathrm{Ag} / \mathrm{AgCl}$, and a GCE (3mm diameter) were served as the counter, reference and working electrodes, respectively. The electrochemical detections were done in $\mathrm{N}_{2}$-saturated $50 \mathrm{mM}, \mathrm{pH} 7.0$ phosphate buffer solution (PBS) at room temperature.

\subsection{Fabrication of IL/GOD/PHC functional membrane modified GCE}

The procedure for the preparation of the GCE was as following [13-19]: At first, the GCE was polished twice with alumina $(1.00,0.30$ and $0.05 \mu \mathrm{m}$, respectively). Then the GCE was treated in 0.2 $\mathrm{M} \mathrm{H}_{2} \mathrm{SO}_{4}$. Thereafter, the electrode was dipped in PBS at $1.70 \mathrm{~V}$ for 3-5 min, washed with water. Then, $3 \mu \mathrm{l}$ of the mixture of PHC $(2 \mathrm{mg} / \mathrm{ml})$ and GOD $(10 \mathrm{mg} / \mathrm{ml})$ (ratio of volume: 1) was coated onto the surface of the electrode, and dried for $24 \mathrm{~h}$ in a refrigerator, $2 \mu \mathrm{IL}$ was dropped on the surface of the electrode, dried and kept in the refrigerator. The electro catalytic detections were done after air bubbling of $5 \mathrm{ml}$ PBS and addition of $20 \mu \mathrm{l}$ different concentration of glucose solution (or real blood sample).

\section{Results and discussion}

Figure 1 shows the preparation process of IL/GOD/PHC modified GCE. TEM image also shows that GOD-PHC nano particles may be formed with an average diameter of $20 \mathrm{~nm}$ (data not shown).

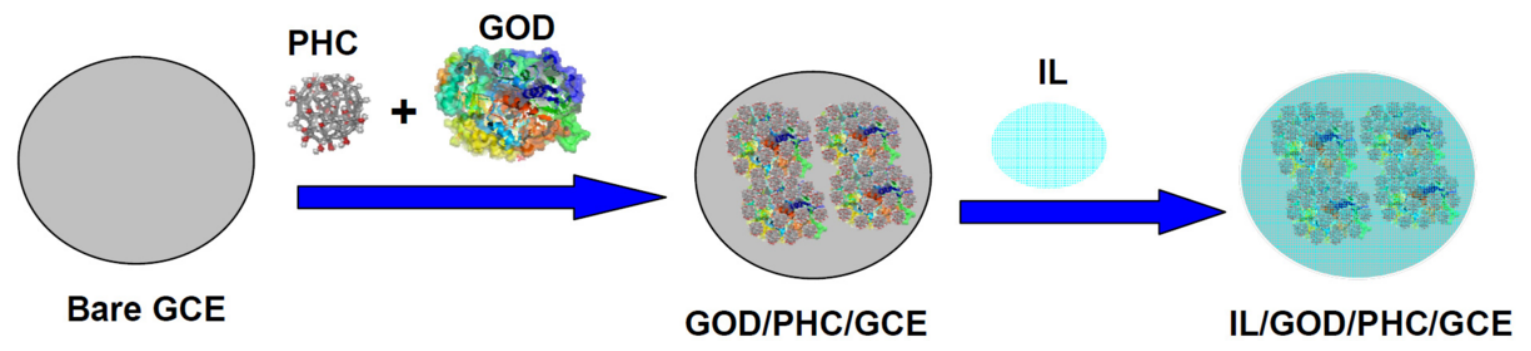

Fig. 1. Preparation process of IL/GOD/PHC modified GCE. 
Figure 2A shows the cyclic voltammograms of bare GCE (a), IL/GOD/GCE (b), IL/PHC/GCE (c) and IL/GOD/PHC/GCE (d). A pair of redox peaks was observed at the IL/GOD/PHC modified GCE. The formal potential $\left(\mathrm{E}^{\circ}\right)$ was $-329 \pm 2 \mathrm{mV}$. This value was greater than the most reported results, for example, the $\mathrm{E}^{\text {ol }}$ obtained at GOD/Au/GCE (-444 mV vs SCE) [16], NF/GOD/CNT/GCE (-464 mV vs $\mathrm{SCE})$ [17] and GOD/PDDA-HCNTs/MGC electrode (-471 mV vs $\mathrm{Ag} / \mathrm{AgCl})$ [18]. Positive potential shift for the electrode may lead to a more efficient electro catalytic reaction [14]. However, no redox peak was observed for the bare GCE (curve a), IL/GOD/GCE (curve b) and IL/PHC/GCE (curve c).

Figure 2(B) shows the cyclic voltammograms (CVs) of IL/GOD/PHC/GCE in $50 \mathrm{mM}$ PBS (pH 7.0) at various scan rates. The peak currents increased linearly with increasing scan rate $(v)$ (Figure $2 \mathrm{C}$ ). The cathodic peak potential $\left(\mathrm{E}_{\mathrm{pc}}\right.$ ) changed linearly versus $\ln v$ from 0.25 to $0.5 \mathrm{~V} / \mathrm{s}$ (Figure 2D), Then, It could be concluded that $n=2$ and $\alpha=0.72$ [20] based on Eq. (1) [21]:
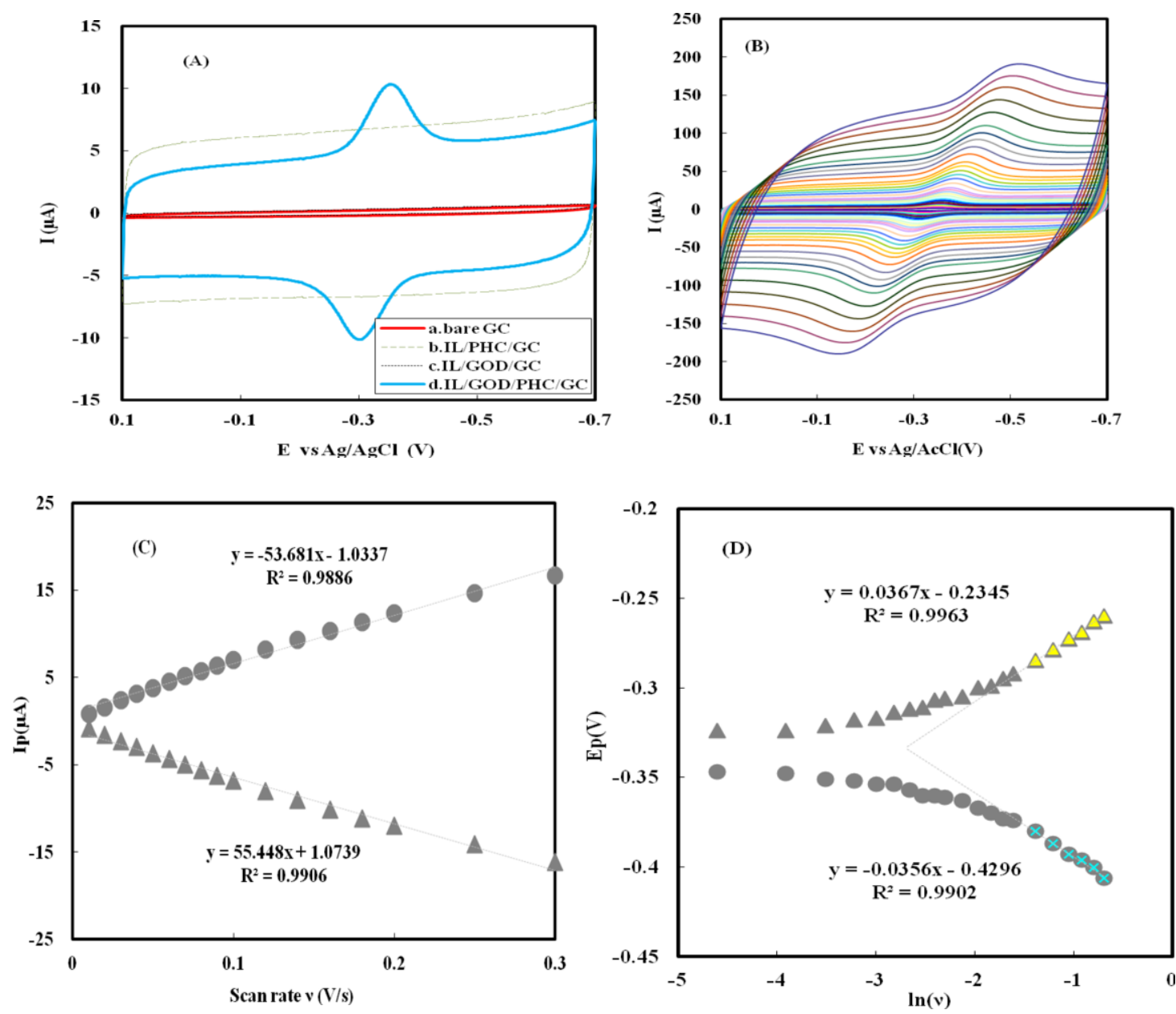

Fig. 2. (A) The cyclic voltammograms (CVs) of different modified electrodes: (a) bare GCE, (b) IL/GOD/GCE; (c) IL/PHC/GCE; (d) IL/GOD/PHC/GCE. The experiments were done in $50 \mathrm{mM}$, pH $7.0 \mathrm{PBS}$ at $0.05 \mathrm{~V} / \mathrm{s}$. (B) CVs of $\mathrm{IL} / \mathrm{GOD} / \mathrm{PHC} / \mathrm{GCE}$ at the scan rate of $0.02,0.03,0.04,0.05, \ldots$ and $2.0 \mathrm{~V} / \mathrm{s}$, respectively. (C) Relationship between peak current $\left(\mathrm{I}_{\mathrm{p}}\right)$ and scan rate $(\mathrm{v})$. (D) Relationship between peak potential $\left(\mathrm{E}_{\mathrm{p}}\right)$ and $\ln v$. 

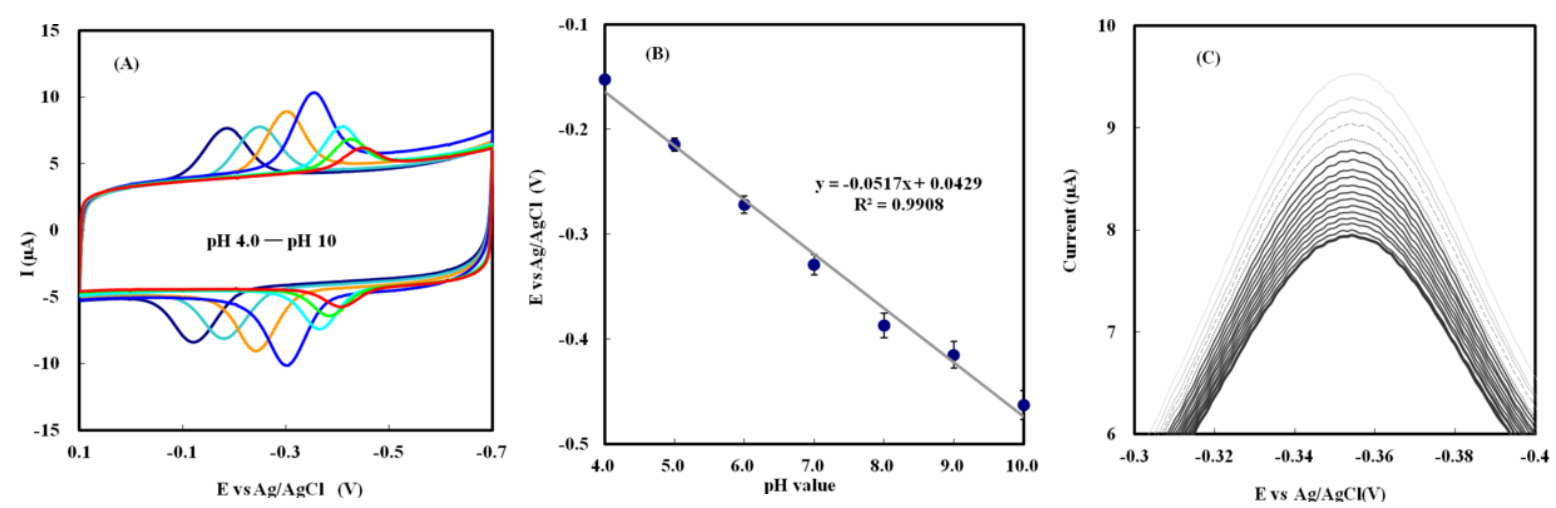

Fig. 3. (A) $\mathrm{CVs}$ of $\mathrm{IL} / \mathrm{GOD} / \mathrm{PHC} / \mathrm{GCE}$ at different $\mathrm{pH}$ values (from left to right): 4.0, 5.0, 6.0, 7.0, 8.0, 9.0 and 10.0, respectively. (B) Plot of formal potential $\left(\mathrm{E}^{\circ}\right.$ ) versus $\mathrm{pH}$ value. (C) The linear sweep voltammograms of IL/GOD/PHC/GCE in $5 \mathrm{ml}, 50 \mathrm{mM}$, pH 7.0 PBS in the absence and presence of $0.02,0.04,0.06,0.08,0.12,0.2,0.25,0.35,0.5,0.8,1.0,1.5,2.0$, 2.5, 3.0, 3.5 and $4.0 \mathrm{mM}$ glucose, respectively. Cleaning of electrode is not needed between samples.

$$
E_{p}=E^{\circ}+\frac{R T}{a n F}-\frac{R T}{a n F} \ln v
$$

where $\mathrm{R}$ is the gas constant, $\mathrm{T}$ is the temperature ( $293 \mathrm{~K}$ here), $\alpha$ the cathodic electron transfer coefficient, $\mathrm{n}$ the number of electrons, and $\mathrm{F}$ the Faraday constant, respectively..

The apparent heterogeneous electron transfer rate constant $\left(\mathrm{k}_{\mathrm{s}}\right)$ was calculated to be $1.43 \mathrm{~s}^{-1}$, using the following equation based on Eq. (2) [22]:

$$
\ln k_{s}=a \ln (1-a)+(1-a) \ln a-\ln \left(\frac{R T}{n F v}\right)-a(1-a) \frac{n F \Delta \mathrm{E} p}{R T}
$$

The concentration ( $\Gamma$ ) of GOD on the GCE was $5.33 \times 10^{-10} \mathrm{~mol} \cdot \mathrm{cm}^{-2}$ based on Eq. (3) [23]:

$$
I_{p}=\frac{n^{2} F^{2} A \Gamma v}{4 R T}
$$

This value of $\Gamma$ is larger than the theoretical $\Gamma$ value of $1.7 \times 10^{-10} \mathrm{~mol} \mathrm{~cm}^{-2}$ based on PDB data of GOD (PDB ID: $1 \mathrm{cf} 3$, about $10 \mathrm{~nm}$ diameter) and the $\Gamma$ value $1.0 \times 10^{-11} \mathrm{~mol} \mathrm{~cm}^{-2}$ based on the TEM image (about $20 \mathrm{~nm}$ diameter, data not shown)

$\mathrm{CVs}$ of IL/GOD/PHC/GCE at different $\mathrm{pH}$ values are shown in Figure 3A. The formal potential $\left(\mathrm{E}^{\mathrm{o}^{\prime}}\right)$ of the modified $\mathrm{GCE}$ was $\mathrm{pH}$ dependent with a slope of $51.7 \mathrm{mV} / \mathrm{pH}$ (Figure 3B). This value was close to the Nernst's value of $59.2 \mathrm{mV}$ [15]. From Figure 3C, it could be seen that the optimized potential for amperometric detection of glucose was $-0.35 \mathrm{~V}$ versus $\mathrm{Ag} / \mathrm{AgCl}[15,19]$. The modified electrode linearly responded to glucose at concentration ranging from $0.02-2.0 \mathrm{mM}$. The detection limit was $1 \mu \mathrm{M}$. This detection limit value was smaller than most reported results [24-28]. The 
apparent Michaelis-Menten constant $\left(\mathrm{K}_{\mathrm{m}}{ }^{\text {app }}\right)$ was calculated to be $1.45 \mathrm{mM}$ from the electrochemical version of the Linewearver-Burk Eq. (4) (data not shown) [19].

$$
\frac{1}{I_{s}}=\frac{1}{I_{\max }}+\frac{K_{m}^{a p p}}{I_{\max } c}
$$

Where, $I_{\mathrm{s}}, I_{\max }$, and c are steady-state current after the addition of glucose, maximum current measured under saturated glucose conditions and glucose concentration, respectively. $\mathrm{K}_{\mathrm{m}}{ }^{\text {app }}$ value was lower than the modified electrodes of PEI/GOD/PGE (7.9 mM) [24], Chit/DNA/GOD/Chit/GC (3.12 $\mathrm{mM})$ [25] and $\mathrm{GOD} / \mathrm{NH}_{2}-\mathrm{TiO}_{2}-\mathrm{CNT} / \mathrm{GC}$ [26], and larger than the modified electrodes of GOD/BCNT/GC electrode $(0.2 \mathrm{mM})$ [27] and GOD-GQD/CC electrode $(0.76 \mathrm{mM})$ [28]. The low $\mathrm{K}_{\mathrm{m}}{ }^{\text {app }}$ value indicates a high affinity of glucose for IL/GOD/PHC/GCE. PHC may reduce the electron transfer distance between FAD group of GOD and the GCE [19].

Electro active species such as ascorbic acid $(0.5 \mathrm{mM})$, uric acid $(0.5 \mathrm{mM})$ and dopamine $(0.5$ $\mathrm{mM}$ ) could cause negligible effect on the glucose detection, and IL/GOD/PHC modified GCE has a good selectivity on the glucose in serum samples (data not shown). The stability of the IL/GOD/PHC/GCE was checked by examining the cyclic voltammetric peak currents of GOD by continuously scanning for about 30 cycles (data not shown). There was nearly no decrease of the voltammetric response, showing that the modified GCE was stable in PBS solution.

\section{Conclusion}

Direct electrochemistry of GOD was achieved when GOD/PHC nano structure was confined on a GCE and protected with IL membrane. The modified GCE could be used as a third generation biosensor for determination of glucose with good sensitivity, stability and selectivity.

\section{Acknowledgement}

The support of Development Projects of Henan Province Science and Technology (No.142300410124) and Henan University Science Foundation is gratefully acknowledged.

\section{References}

[1] H.W. Kroto, J.R. Heath, S.C. O’Brien, R.F. Curl and R.E. Smalley, C60: Buckminsterfullerene, Nature 318 (1985), $162-163$.

[2] S. Iijima, Helical microtubules of graphitic carbon, Nature 354 (1991), 56-58.

[3] S.D. Chambers, T.W. Holcombe, F. Svec and J.M.J. Fréchet, Porous polymer monoliths functionalized through copolymerization of a C60 fullerene-containing methacrylate monomer for highly efficient separations of small molecules, Analytical Chemistry 83 (2011), 9478-9484.

[4] J.R. Baena, M. Gallego and M. Valcárcel, Fullerenes in the analytical sciences, TrAC Trends in Analytical Chemistry 21 (2002), 187-198.

[5] L.A. Kartsova and A.A. Makarov, New fullerene-based stationary phases for gas chromatography, Journal of Analytical Chemistry 59 (2004), 724-729. 
[6] L.Y. Chiang, J.W. Swirczewski, C.S. Hsu, S.K. Chowdhury, S. Cameron and K. Creegan, Multi-hydroxy additions onto C60 fullerene molecules, Journal of the Chemical Society, Chemical Communications 24 (1992), 1791-1792.

[7] L.Y. Chiang, J.B. Bhonsle, L. Wang, S.F. Shu, T.M. Chang and J.R. Hwu, Efficient one-flask synthesis of water soluble [60] fullerenols, Tetrahedron 52 (1996), 4963-4972.

[8] Y.M. She, Y.P. Ji, Y.F. He and S.Y. Liu, Detection of specific noncovalent protein-fullerenols complexes by matrix-assisted laser desorption ionization mass spectrometry, Chemical Journal of Chinese Universities 19 (1998), $1735-1738$

[9] U. Schroder, J.D. Wadhawan, R.G. Compton, F. Marken, P.A.Z. Suarez and C.S. Consorti, Water-induced accelerated ion diffusion: Voltammetric studies in 1-methyl-3-[2,6-(S)-dimethylocten-2-yl]imidazolium tetrafluoroborate, 1-butyl-3-methylimidazolium tetrafluoroborate and hexafluorophosphate ionic liquids, New Journal of Chemistry 24 (2000), 1009-1015.

[10] J. Dupont, On the solid, liquid and solution structural organization of imidazolium ionic liquids, Journal of the Brazilian Chemical Society 15 (2004), 341-350.

[11] E. Feher, B. Major, K. Belafi-Bako' and L. Gubicza, On the background of enhanced stability and reusability of enzymes in ionic liquids, Biochemical Society Transactions 35 (2007), 1624-1627.

[12] F. van Rantwijk, F. Secundo and R.A. Sheldon, Structure and activity of Candida antarctica lipase B in ionic liquids, Green Chemistry 8 (2006), 282-286.

[13] B.L. Xiao, J. Hong, Y.F. Gao, T. Yang, A.A. Moosavi-Movahedi and H. Ghourchian, Direct electron transfer of horseradish peroxidase on a functional nanocomplex modified glassy carbon electrode, Bio-Medical Materials and Engineering 24 (2014), 1079-1084.

[14] J. Hong, Y.X. Zhao, B.L. Xiao, A.A. Moosavi-Movahedi, H. Ghourchian and N. Sheibani, Direct electrochemistry of hemoglobin immobilized on a functionalized multi-walled carbon nanotubes and gold nanoparticles nanocomplex-modified glassy carbon electrode, Sensors 13 (2013), 8595-8611.

[15] J. Hong, W.Y. Yang, Y.X. Zhao, B.L. Xiao, Y.F. Gao, T. Yang, H. Ghourchian, Z. Moosavi-Movahedi, N. Sheibani, J.G. Li and A.A. Moosavi-Movahedi, Catalase immobilized on a functionalized multi-walled carbon nanotubes -gold nanocomposite as a highly sensitive bio-sensing system for detection of hydrogen peroxide, Electrochimica Acta 89 (2013), 317-325.

[16] C. Qiu, X. Wang, X. Liu, S. Hou and H. Ma, Direct electrochemistry of glucose oxidase immobilized on nanostructured gold thin films and its application to bioelectrochemical glucose sensor, Electrochimica Acta 67 (2012), 140-146.

[17] C. Cai and J. Chen, Direct electron transfer of glucose oxidase promoted by carbon nanotubes, Analytical Biochemistry 332 (2004), 75-83.

[18] R. Cui, Z. Han, J. Pan, E.S. Abdel-Halim and J. J. Zhu, Direct electrochemistry of glucose oxidase and biosensing for glucose based on helical carbon nanotubes modified magnetic electrodes, Electrochimica Acta 58 (2011), 179-183.

[19] J. Hong, A.A. Moosavi-Movahedi, H. Ghourchian and A. Molaei Rad, Direct electron transfer of horseradish peroxidase on Nafion-cysteine modified gold electrode, Electrochimica Acta 52 (2007), 6261-6267.

[20] H. Ma, N. Hu and J.F. Rusling, Electroactive myoglobin films grown layer-by-layer with poly (styrenesulfonate) on pyrolytic graphite electrodes, Langmuir 16 (2000), 4969-4975.

[21] E. Laviron, Adsorption, autoinhibition and autocatalysis in polarography and in linear potential sweep voltammetry, Journal of Electroanalytical Chemistry 52 (1974), 355-393.

[22] E. Laviron, General expression of the linear potential sweep voltammogram in the case of diffusionless electrochemical systems, Journal of Electroanalytical Chemistry 101 (1979), 19-28.

[23] P. Rahimi, H. Rafiee-Pour, H. Ghourchian, P. Norouzi and M.R. Ganjali, Ionic liquid/NH2-MWCNTs as a highly sensitive nano-composite for catalase direct electrochemistry, Biosensors and Bioelectronics 25 (2010), 1301-1306.

[24] W. Zhang, Y. Huang, H. Dai, X. Wang, C. Fan and G. Li, Tuning the redox and enzymatic activity of glucose oxidase in layered organic films and its application in glucose biosensors, Analytical Biochemistry 329 (2004), 85-90.

[25] T. Gu, Y. Zhang, F. Deng, J. Zhang and Y. Hasebe, Direct electrochemistry of glucose oxidase and biosensing for glucose based on DNA/chitosan film, Journal of Environmental Sciences 23 (2011), S66-S69.

[26] M. Tasviri, H. A. Rafiee-Pour, H. Ghourchian and M. R. Gholami, Amine functionalized $\mathrm{TiO}_{2}$ coated on carbon nanotube as a nanomaterial for direct electrochemistry of glucose oxidase and glucose biosensing, Journal of Molecular Catalysis B 68 (2011), 206-210.

[27] C. Deng, J. Chen, X. Chen, C. Xiao, L. Nie and S. Yao, Direct electrochemistry of glucose oxidase and biosensing for glucose based on boron-doped carbon nanotubes modified electrode, Biosensors and Bioelectronics 23 (2008), $1272-1277$.

[28] Q. Liu, X. Lu, J. Li, X.Yao and J. Li, Direct electrochemistry of glucose oxidase and electrochemical biosensing of glucose on quantum dots/carbon nanotubes electrodes, Biosensors and Bioelectronics 22 (2007), 3203-3209. 